\title{
BUNG HATTA, PROKLAMATOR, ILMUWAN, PENULIS DAN KARYA-KARYANYA: SEBUAH ANALISIS BIO-BIBLIOMETRIK
}

\author{
Maryono*
}

\begin{abstract}
Bung Hatta was the proclaimer of independence, first vice president of the Republic of Indonesia. He was also a scientist and a very prolific writer, with his work in various fields of study. His works discuss economic issues, cooperation, politics, law, philosophy, religion, and others. Out of 163 titles of his writings, 69 titles (42\%) are available in Hatta Corner, not including translations and works that may still be issued. Bibliographic data of his works are largely obtained from the online catalog of various institutions; i.e. OCLC World Cat 46 titles, Bibliography by the Idayu Foundation 26 titles, NLA 8 titles, Hathitrust 5 titles, the National Library of the Republic of Indonesia 4 titles, JSTOR 4 titles, and Bibliotheek Arnhem 1 title. There are 8 titles of Bung Hatta's works that have been translated into various languages, including Bung Hatla defense manuscript while he was in jail and would face the Hague tribunal, in March 1928, entitled "Indonesie Vrij!". His most productive period was in the decade of 1951-1960, aged 49-58, with as many as 47 titles of writing. His greatest contributions were in the field of human rights, political and social economy. His works became guide for the governance of the Republic of Indonesia.
\end{abstract}

Keywords: Mohammad Hatta, Bung Hatta, Proclaimer, Productivity, Authorship, Bio-bibliometrics * Pustakawan UGM

\section{A. PENDAHULUAN}

Dalam buku biografi Bung Hatta oleh Imran (1981), disebutkan bahwa Bung Hatta atau namalengkapnya Dr. Mohammad Hatta dilahirkan di Bukittinggi, Sumatera Barat, 12 Agustus 1902, dan wafat pada 14 Maret 1980. Bung Hatta menyelesaikan sekolah Europeese Lagere School (ELS) pada tahun 1916. Selanjutnya tahun 1919 Bung Hatta lulus dari Meer Uitgebreid Lagere Onderwijs (MULO) di Padang. Sekolah berikutnya adalah Prins Hendrik School, dan lulus tahun 1921. Bung Hatta mengikuti kuliah di Handels Hoogere School (Sekolah Tinggi Ekonomi) di Rotterdam Belanda, pada jurusan ekonomi perdagangan, kemudian pindah jurusan ckonomi kenegaraan. Bung Hatta menyelesaikan kuliahnya tahun 1932, dengan gelar sarjana ekonomi.

Pengalaman berorganisasi Bung Hatta dimulai dengan menjadi anggota klub sepak bola Swallow semasa sekolah MULO di Padang, dan kemudian menjadi bendahara. Pada akhir tabun 1917, Bung Hatta dipilih sebagai bendahara Jong Sumatranen Bond (JSB) Padang. Beliau dianggap sudah berpengalaman dalain bidang keuangan, juga seorang yang jujur. Pada waktu beliau sekolah di Jakarta, dipilih sebagai bendahara JSB pusat. JSB pusat menerbitkan majalah Jong Sumatra yang sedang dalam kondisi kesulitan keuangan, dan di tangan beliau, kesulitan dapat teratasi dan majalah dapat diterbitkan kembali. Nama Hatta semakin dikenal oleh para mahasiswa Indonesia di Belanda, yaitu perkumpulan Indische Vereniging yang didirikan pada tahun 1908 , yang kemudian berganti namanya menjadi Indonesische Vereniging dan kemudian berganti nama lagi menjadi Perhimpunan Indonesia (PI). Setelah tiba di Belanda, Bung Hatta diangkat sebagai bendahara. Karena berpengalaman memimpin majalah, maka beliau diserahi tugas memimpin majalah Hindia Putra, yang diterbitkan oleh perkumpulan tersebut. Hindia Putra kemudian berganti nama menjadi Indonesia Merdeka.Pada tahun 1923 Bung Hatta dipilih menjadi bendahara, karena sangat cemerlang, pada tahun 1926 beliau dipilih sebagai ketua PI sampai dengan tahun 1931.

Pada tanggal 25 September 1927 Bung Hatta ditangkap Belanda, beliau dituduh telah menjadi scorang komunis. Bung Hatta dituduh pula menghasut rakyat supaya memberontak. Beliau diadili pada sidang pertama tanggal 8 Maret 1928. Di dalam penjara Bung I Iatta menyusun naskah pembelaan, yang akan diueapkan di pengadilan. Sidang ke dua pada tanggal 28 Maret 1928 Bung Hatta membacakan naskah pembelaannya dalam bahasa Bclanda dengan judul "Indonesia Vrij". 
Naskah pembelaan setebal 94 halaman tersebut kini di simpan dalam bentuk buku digital fullteks oleh Perpustakaan kota Arnhem, Belanda (Bibliotheek Arnhem), dengan judul "Indonesie Vrij" tertanggal 28 September 1928. Isi naskah tersebut adalah uraian nasib bangsa lndonesia akibat penjajahan Belanda, uraian tujuan PI, PI tidak memakai kekerasan dan tidak menghasut untuk memberontak, perjuangan $\mathrm{PI}$ adalah perjuangan politik untuk melenyapkan penjajahan Belanda. Dalam buku "Mengenang Bung Hatta", sekretaris pribadi Bung Hatta yaitu Widjaja (1988), menyebutkan bahwa Bung Hatta adalah tokoh pergerakan Nasional. Sejarah perjuangan bangsa Indonesia mengalami perubahan yang cukup mendasar sejak lahirnya organisasi-organisasi pergerakan yang dipelopori oleh Budi Utomo dan Sarekat Dagang Islam. Perjuangan memasuki era baru, yaitu corak perjuangan tidak lagi menggunakan kekerasan senjata, lebih menekankan perjuangan lewat organisasi politik yang teratur, dan dirasakan kesadaran baru arti pentingnya persatuan dan kesatuan, serta perjuangan secara serentak di berbagai daerah di seluruh Indonesia. Bung Hatta memberi andil yang besar dalam memajukan kegiatan pergerakan politik.

Shadily (1982) menyebutkan bahwa pada tahun 1927-1931 Bung Hatta menjadi anggota pucuk pimpinan Liga Melawan Imperialisme dan Penjajahan, berkedudukan di Berlin, mewakili Indonesia. Bung Hatta juga menghadiri Kongres Democratique International di Beirville (Paris) pada tahun 1936. Sekembali ke tanah air, dan setelah mengundurkan diri dari PI, 1933-1934 Bung Hatta menjadi ketua Pendidikan Nasional Indonesia (PNI Baru), yang menerbitkan majalah Daulat Ra'jat. Bung Hatta dipenjarakan pemerintah Belanda pada tahun 1934-1935, dan dibuang ke Boven Digul lrian Jaya pada tahun 1935-1936. Pada tahun 1936-1942 Bung Hatta dipindah ke Bandaneira, kemudian tahun 1942 dipindah lagi ke Sukabumi, dan dibebaskan pada 9 Maret 1942. Pada bulan April 1942, beliau menjadi kepala kantor penasehat pada kantor pemerintah Balatentara Dai Nippon. Ensiklopedi tokoh Indonesia (2002) menyebutkan bahwa Bung Hatta menjadi anggota Badan Penyelidik Usahausaha Persiapan Kemerdekaan Indonesia pada Mei 1945, kemudian menjadi wakil ketua Panitia Persiapan Kemerdekaan Indonesia pada 7 Agustus 1945, dan dituntaskan sebagai Proklamator Kemerdekaan RI pada 17 Agustus 1945. Bung Hatta menjadi wakil Presiden RI pertama pada 18 Agustus 1945, tetapi pada Januari 1948 - Desember 1949 menjabat Wapres sekaligus merangkap Perdana Menteri dan Menteri Pertahanan. Bung Hatta menjadi ketua delegasi Indonesia pada konferensi meja bundar di Den Haag dan menerima penyerahan kedaulatan dari Ratu Juliana pada 1949. Jabatan berikutnya adalah Wapres merangkap Perdana Menteri dan Menteri Luar Negeri Kabinet RIS pada Desember 1949-Agustus 1950, kemudian mengundurkan diri dari jabatan wapres pada 1 Desember 1956. Bung Hatta menjadi penasehat Presiden dan Penasehat Komisi IV tentang masalah korupsi pada 1969 dan menjadi Ketua Panitia Lima yang bertugas memberikan perumusan penafsiran mengenai Pancasila pada 1975.

Bung Hatta sangat berjasa mengembangkan bidang pendidikan. Sepulang dari negeri Belanda, Bung Hatta memberikan kursus untuk para kader PNI baru. Setelah Indonesia merdeka, sejak tahun 1950 Bung Hatta mulai mengajar di SSKAD (Sekolah Staf Komando Angkatan Darat) di Bandung dan di beberapa Universitas yang sudah ada waktu itu, antara lain Universitas Gadjah Mada dan Universitas Indonesia. Tempat beliau mengajar lainnya setelah mengundurkan diri dari wakil presiden ialah di Universitas Padjadjaran dan Universitas Hasanuddin. Sewaktu memegang jabatan sebagai wakil presiden, dalam tahun 1950an, beliau mengajar di Fakultas Ekonomi dan Fakultas Sosial Politik UGM. Dalam satu bulan, seminggu penuh diabdikan untuk mengajar di UGM.

Konggres Koperasi Indonesia di Bandung, Juli 1953 menetapkan Bung Hatta sebagai Bapak Koperasi Indonesia. Bung Hatta orang pertama yang gigih mengusahakan konsep koperasi Indonesia untuk dijadikan tulang punggung perekonomian rakyat Indonesia. Bung Hatta adalah yang merumuskan pasal 33 Undang-Undang Dasar 1945, disamping merumuskan beberapa pasal lainnya. Pasal ini pada prinsipnya mengatur dan sekaligus menjadi dasar utama bagi politik perekonomian dan politik sosial Negara Rl. Beliau juga tidak hentihentinya terjun langsung ke lapangan, ikut membina dan menumbuhkan koperasi dari bawah.

Bung Hatta selain sebagai proklamator kemerdekaan RI, wakil presiden RI pertama, Bung Hatta adalah juga ahli ekonomi, ahli ilmu Negara, ahli ilmu politik, sebagai ilmuwan dan intelektual sejati yang aktif menulis di berbagai media. Menurut Widjaja (1988), terdapat suatu ungkapan yang meresap dalam cara berpikir Bung Hatta: "Dalam perbedaan pendapat, maka lahirlah kebenarankebenaran baru". Ungkapan tersebut dianggap sebagai cerminan sikap demokratis Bung Hatta, 
sebagai intelektual dalam menanggapi perbedaan pendapat. Bung Hatta menguasai beberapa bahasa asing, antara lain bahasa Inggris, Belanda, Jerman, dan Perancis, karena itu mudah berkomunikasi dan menulis. Semasa masih aktif dalam organisasi pergerakan, beliau telah menulis ke berbagai surat kabar, diantaranya Hindia Poetra, Neratja, Surat kabar PN1-baru, Daoelat Ra'jat. Karya-karya Bung Hatta berupa buku lebih kurang 69 judul buku, serta sejumlah brosur yang belum diterbitkan. Buku karya Bung Hatta tersebut dapat dibaca di Perpustakaan Yayasan ldayu dan di Perpustakaan Yayasan Hatta (Hatta Corner UGM). Buku yang diterbitkan kemudian adalah kumpulan-kumpulan pidato, yang juga terdapat di Hatta Corner UGM. jumlah karya tersebut terlihat bahwa Bung Hatta adalah seorang ilmuwan dan penulis yang produktif. Karena jasajasa dan karya-karyanya itulah, pada 27 November 1956, Universitas Gadjah Mada menganugerahkan gelar Doctor Honoris Causa. Pada periode berikutnya, Universitas Indonesia menganugerahkan gelar Doctor Honoris Causa dalam bidang ilmu hukum pada 30 Agustus 1975. Kemudian pada 10 September 1974, Universitas Hasanuddin menganugerahkan gelar serupa tetapi dalam bidang ilmu ekonomi. Sedangkan Universitas Padjdjaran selain menganugerahkan gelar Doctor Honoris Causa, juga mengangkat beliau sebagai guru besar luar biasa dalam bidang politik perekonomian.

Karya-karya Bung Hatta berupa buku, yang terdata di Hatta Corner berjumlah 69 judul, scdangkan karya tentang Bung Hatta oleh penulis lain berjumlah 24 judul. Sedangkan di perpustakaan dan sumber lainnya diperkirakan masih banyak yang belum terdata. Menurut data di sumber database jurnal historis di JSTOR, terdapat 4 artikel karya Bung Hatta, dimuat di jurnal ilmiah dengan tahun terbit 1953-1965. Database Ebsco memuatl judul artikel karya Bung Hatta. Bung Hatta sangat produktif, menulis banyak buku, artikel, naskah pidato dan lain-lain. Ditinjau dari ilmu bibliometrik, Bung Hatta memiliki produktivitas menulis yang tinggi, tetapi belum pernah dilakukan kajian produktivitas dan bibliometrik lainnya. Untuk itu penelitian yang mengkaji tokoh besar proklamator, ilmuwan dan penulis tersebut sangat diperlukan.

\section{Rumusan Masalah}

Berdasarkan uraian tersebut di atas maka dalam kajian ini akan mengungkap yaitu

1) Apa saja jenis-jenis karya Bung Hatta dan kontribusinya,
2) Apakah subyek kajian karya Bung Hatta di Hatta Corner?,

3) Bagaimanakah produktivitas Bung Hatta sebagai penulis?

4) Bagaimanakah penerbitan karya Bung Hatta selama berkarya?

\section{Tujuan Penelitian}

Berdasarkan rumusan masalah tersebut di atas, maka kajian ini bertujuan

1) Untuk mengetahui jenis-jenis karya Bung Hatta dan kontribusinya.

2) Untuk mengetahui subyek karya yang dihasilkan, di Hatta Corner.

3) Untuk mengetahui produktivitas Bung Hatta sebagai penulis.

4) Untuk mengetahui penerbitan karya-karya Bung Hatta selama berkarya.

\section{Manfaat Penelitian}

Penelitian ini diharapkan bermanfaat untuk:

1) Memberikan informasi kepadamasyarakat terhadap tokoh besar perjuangan bangsa (proklamator), Bung Hatta juga sebagai seorang ilmuwan dan penulis produktif.

2) Memberikan inspirasi dan contoh bagi generasi penerus.

3) Menambah kajian keilmuan bio-bibliometrik bagi pustakawan.

\section{B. TINJAUAN PUSTAKA Penelitian Terdahulu}

Penelitian bio-bibliometrik pernah dilakukan oleh beberapa peneliti terhadap tokoh ilmuwan dan karya-karyanya di bidang keahlian masing-masing. Parvathamma, dkk. (2013), meneliti kontribusi riset Prof Atul H. Chokshi, seorang ilmuwan terkenal di bidang ilmu material asal India. Selama masa produktifnya, menghasilkan 76 karya yang dipublikasikan di jurnal internasional ternama, dan 34 artikel di prosiding konferensi, dengan total 2.820 sitiran, yang diperoleh dari publikasi tersebut. Rerata produktivitas ilmiah tahunan adalah 4 karya riset, dan diperoleh 113 sitiran per tahunnya. Rerata sitiran adalah 26 sitiran per publikasi. Sebuah artikelnya yang dipublikasikan di jurnal Material Scienceand Engineering R-Reports, dengan impact factor 04.79, memperoleh sitiran sebanyak $207 \mathrm{kali}$, yang merupakan sitiran tertinggi di antara publikasi 
risetnya, dan menunjukkan tokoh tersebut dapat menjadi contoh yang mendorong prestasi para peneliti muda. Dalam sebuah penelitian bibliometriknya, Kademani dkk. (2001) menganalisis 246 karya Ahmed Hassan Zewail, tokoh peraih hadiah Nobel di bidang Kimia tahun 1999. Karya-karya tersebut diterbitkan antara tahun 1976 - 1994, dalam kurun waktu masa produktif selama 19 tahun. Penelitian tersebut menghasilkan beberapa temuan, dari 246 karya, 62 tentang femtochemistry, 56 tentang reaction rates and IVR, serta 49 tentang general review. Koefisien produktivitas mencapai 0,52 yang menunjukkan konsistensi produktivitas publikasi selama masa aktif meneliti. Baby, K. dan J.P.S. Kumaravel (2012), melaksanakan analisis biobibliometrik terhadap karya-karya Prof. M. Lakshmanan, seorang peneliti nonlinear dynamics, bidang Fisika, berkebangsaan India. Dalam kurun waktu 1972 - 2011, tokoh tersebut mempublikasikan 225 artikel ilmiah hasil risetnya di 46 jurnal dengan impact factor tinggi. Derajat kolaborasinya mencapai 0,56 dan Journal of mathematical physics merupakan jurnal utama tempat mempublikasikan karya-karyanya. Analisis biobibliometrik juga dilakukan oleh Koganuramath dkk. (2004) terhadap karya-karya Wolfgang Ketterle ilmuwan peraih Nobel Fisika pada tahun 2001. Publikasinya mencapai 115 dalam kurun waktu 1982 - 2002, sedangkan koefisien produktivitasnya mencapai 0,78 . Karya-karyanya tersebar di 24 jurnal ilmiah, dan mendapatkan berbagai penghargaan termasuk hadiah Nobel Fisika pada tahun 2001.

Penelitian bio-bibliometrik terhadap Bung Hatta sebagaitokoh besar proklamator, ilmuwan dan penulis belum pernah dilakukan sebelumnya. Untuk itu penulis mengkaji bio-bibliometrik terhadap karya Bung Hatta berdasarkan Koleksi yang ada di Hatta Corner UGM, bibliografi karya Bung Hatta oleh Yayasan Idayu, dan Menelusur karya Bung Hatta di beberapa sumber: Katalog online Perpustakaan Nasional, OCLC World catalog, Database JSTOR, EBSCO, Hathitrust, National Library of Australia, Bibliotheek Arnhemdan internet.

\section{Bibliometrik}

Dalam buku "Dictionary of Bibliometrics" karya Diodato (1994) bibliometri didefinisikan sebagai berikut:

"Bibliometrics is a field that uses mathematical and statistical techniques, from counting to calculus, to study publishing and communication patterns in the distribution of information".
Bibliometri adalah suatu bidang ilmu yang menggunakan teknik matematika dan statistika, dari penghitungan sederhana sampai kalkulus, untuk mempelajari publikasi dan pola komunikasi dalam distribusi informasi. Bibliometri didefinisikan juga oleh Reitz dalam kamus ODLIS sebagai penerapan matematika dan metode statistik untuk mempelajari dan mengidentifikasi pola-pola penggunaan koleksi dan jasa perpustakaan, atau untuk menganalisis sejarah pengembangan literatur, khususnya aspek authorship, publikasi dan penggunaannya. Menurut Sulistyo-Basuki (2002), pada dasarnya bibliometrika terbagi atas dua kelompok besar yaitu kelompok yang mengkaji distribusi publikasi dan kelompok yang membahas analisis sitiran / sitasi (citation analysis). Kelompok pertama merupakan analisis kuantitatif terhadap literatur ditandai dengan munculnya tiga "dalil " dasar bibliometrika yaitu dalil Lotka (1926) yang menghitung distribusi produktivitas berbagai pengarang, dalil Zipf (1933) yang memberi peringkat kata dan frekuensi dalam literatur, serta Bradford's law of scattering yang mendeskripsi dokumen (biasanya majalah) dalam disiplin tertentu. Kelompok ke dua ditandai dengan munculnya karya Garfield yang dianggap sebagai tonggak dalam analisis sitasi. Hartinah (2002) menerangkan bahwa analisis sitiran adalah penyelidikan melalui data sitiran dari suatu dokumen, baik dokumen yang disitir maupun dokumen yang menyitir. Metode ini umumnya digunakan untuk menyelidiki pengarang, subjek dan sumber dokumen terdiri dari nama jurnal, serta tahun terbit. Penelitian sitiran juga sering digunakan untuk mengetahui jenis literatur yang disitir, literatur yang paling banyak disitir, pengarang yang paling banyak disitir, sitasi per peneliti, sitasi per artikel, ketersediaan literatur, bahasa literatur yang disitir, lama keusangan literatur yang disitir (half-life), kemutakhiran literatur yang disitir (currentness), cara penulisan sitasi, immediacy index, serta impact factor.

\section{Bio-bibliometrik}

Baby dan Kumaravel (2012) menjelaskan bahwa metode biobibliometrik berhubungan dengan studi bibliografis terhadap karir individu seorang tokoh peneliti / ilmuwan dan menghubungkan analisis studi bibliografis tersebut dengan pencapaian akademisnya. Sin (1999) juga menyebutkan bahwa bio-bliometrik adalah studi biografi seorang tokoh dihubungkan dengan analisis bibliometrik publikasi yang dihasilkannya. Istilah 
"bio-bibliometrics" pertama kali digunakan oleh Sen dan Gan (1990), dimaksudkan scbagai metode kuantitatif dan analisis untuk menemukan dan menentukan hubungan antara unsur bio-data dan biblio-data dari seorang tokoh.

\section{Produktivitas}

Kajian produktivitas peneliti dilakukan dengan analisis sitiran, yang biasanya ditunjukan dengan menentukan angka: jumlah artikel per peneliti, artikel per tahun, artikel per peneliti per tahun,serta peneliti paling produktif (most prolific author), sebagaimana telah dilakukan oleh Sutardji (2012). Dalam penelitian tersebut, jumlah peneliti dimaksud adalah peneliti yang terdapat dalam lembaga penelitian tertentu. Kajian produktivitas jika dikaitkan dengan seorang tokoh (bio - bibliometrik) maka, studi pada umumnya juga mengkaji masa produktif secara akumulatif (year wise) dari tokoh tersebut, disertai dengan masa paling produktif.

\section{METODE PENELITIAN}

Bung Hatta tokoh Proklamator Kemerdekaan RI dipilih sebagai obyek penelitian karena beliau juga seorang tokoh ilmuwan dan penulis yang menghasilkan banyak karya, berupa buku, konferensi, artikel, naskah pidato yang dibukukan dan lain-lain. Dalan penelitian ini, karya yang diterjemahkan ke dalam berbagai bahasa, dihitung sebagai satu judul karya, untuk menghindari kerancuan dalam penghitungan. Pengumpulan data dilakukan dengan beberapa langkah:

1. Menyusun daftar karya Bung Hatta yang ada di Hatta Corner UGM,

2. Mengecek bibliografi karya Bung Hatta oleh Yayasan ldayu,

3. Menelusur karya Bung Hatta di beberapa sumber: Katalog online Perpustakaan Nasional, OCLC World catalog, Database JSTOR, EBSCO, Hathitrust, National Library of Australia, Bibliotheek Arnhemdan internet.

4. Melakukan tabulasi yang terdiri dari:

a. Tabel 1 daftar karya Bung Hatta

\begin{tabular}{|l|l|l|l|l|l|l|l|}
\hline No. & Judul & No. Klas & Kota terbit & Penerbit & $\begin{array}{l}\text { Tahun } \\
\text { terbit }\end{array}$ & Jurnal & Sumber \\
\hline
\end{tabular}

b. Tabel 2 Sumber data bibliografi

\begin{tabular}{|l|l|c|c|}
\hline No. & Sumber & Jumlah & Persentase \\
\hline
\end{tabular}

c. Tabel 3 jenis karya Bung Hatta

\begin{tabular}{|l|l|l|l|}
\hline No. & Jenis karya & Jumlah & Keterangan \\
\hline
\end{tabular}

d. Tabel 4 subyek karya Bung Hatta

\begin{tabular}{|l|l|l|l|l|l|l|l|l|l|l|}
\hline No.klas/subyek & 000 & 100 & 200 & 300 & 400 & 500 & 600 & 700 & 800 & 900 \\
\hline Jumlah & & & & & & & & & & \\
\hline
\end{tabular}

e. Tabel 5 produktivitas tiap tahun akumulatif

\begin{tabular}{|l|l|l|l|l|}
\hline No. & Tahun & Jumlah karya & Akumulatif & Usia \\
\hline
\end{tabular}

f. Tabel 6 produktivitas per dasa warsa

\begin{tabular}{|l|l|l|l|}
\hline No. & Dasa warsa & Usia & Jumlah karya \\
\hline
\end{tabular}

g. Tabel 7 Tempat terbit

\begin{tabular}{|l|l|l|l|}
\hline No. & Kota & Jumlah & DN/LN \\
\hline
\end{tabular}

h. Tabel 8 penerbit

\begin{tabular}{|c|c|c|c|c|}
\hline No. & Penerbit & Jumlah & & \\
\hline \multicolumn{5}{|c|}{ i. Tabel 9 penerbitan jurnal } \\
\hline No & Judul artikcl & Jurnal & Penerbit & Sumbe \\
\hline
\end{tabular}

j. Tabel 10 karya yang diterjemahkan

\begin{tabular}{|c|l|l|l|l|l|}
\hline No & Judul & No.Klas/subyek & Impresum & Bhs & Sumber \\
\hline
\end{tabular}




\section{HASILDAN PEMBAHASAN}

Sepanjang hidupnya, dalam rentang waktuantara tahun 1902-1980, bung Hatta telah menghasilkan 163 judul karya, terdiri dari 159 buku dan 4 artikel jurnal. Sebagian besar karya Bung Hatta diterbitkan di Indonesia, dan sebagian lagi terbit di luar negeri.

\section{Karya Bung Hatta}

Meskipun Perpustakaan Yayasan Hatta adalah perpustakaan yang menyimpan dan mengelola karya-karya beliau, tetapi karya beliau yang tersimpan di Hatta Corner Perpustakaan UGM hanya 69 judul, atau hanya $42 \%$. jumlah 69 judul itupun, terdapat 1 judul yang fisik bukunya belum ditemukan, meskipun terdapat datanya $\mathrm{di}$ katalog perpustakaan.

Tabel 1. Daftar karya Bung Hatta

\begin{tabular}{|c|c|c|c|c|c|c|c|c|}
\hline No. & Judul & No. Klas & $\begin{array}{l}\text { Kota } \\
\text { terbit }\end{array}$ & Penerbit & $\begin{array}{l}\text { Tahun } \\
\text { terbit }\end{array}$ & Jurnal & Sumber & Ket \\
\hline.- & …......... & $\ldots \ldots$ & ........ & ......... & ........ & $\ldots$. & $\ldots \ldots$ & ...... \\
\hline 161 & $\begin{array}{l}\text { Untuk negeriku : sebuah } \\
\text { otobiografi / Mohammad } \\
\text { Hatta }\end{array}$ & 920 & Jakarta & $\begin{array}{l}\text { Penerbit } \\
\text { Buku } \\
\text { Kompas, }\end{array}$ & 2011 & & NLA & \\
\hline 162 & Uraian Pancasila & 320.1 & Jakarta & Mutiara & 1977 & & Idayu & \\
\hline 163 & $\begin{array}{l}\text { Verspreide Geschriften } \\
\text { Van Mohammad Hatta }\end{array}$ & $\begin{array}{l}081 \text { Hat v } \\
\text { c. } 1\end{array}$ & Djakarta & $\begin{array}{l}\text { CPJ Van } \\
\text { der Peet }\end{array}$ & 1952 & & $\begin{array}{l}\text { Hatta } \\
\text { corner }\end{array}$ & \\
\hline
\end{tabular}

Sumber Data Bibliografi Karya Bung Hatta

Sebagian besar karya beliau di Hatta Corner UGM telah dialihmediakan mengingat kondisi fisik kertas dan jilid yang rusak. Data bibliografi karyakarya Bung Hatta justru banyak terdapat juga di
OCLC Worldcat sejumlah 46 judul, atau 28\%, termasuk karya yang baru diterbitkan. Sumber berikutnya adalah bibliografi karya Bung Hatta oleh Yayasan Idayu, sejumlah 26judul atau 15\%.

Tabel 2. Sumber data bibliografi karya Bung Hatta

\begin{tabular}{|c|c|c|c|}
\hline No. & Sumber & Jumlah & Persentase (\%) \\
\hline 1 & Hatta corner Perpustakaan UGM & 69 & 42,33 \\
\hline 2 & OCLC World Catalog & 46 & 28,22 \\
\hline 3 & Bibliografi karya Bung Hatta oleh Yayasan Idayu & 26 & 15,95 \\
\hline 4 & National Library of Australia & 8 & 4,91 \\
\hline 5 & Hathitrust & 5 & 3,07 \\
\hline 6 & Katalog online Perpustakaan Nasional RI & 4 & 2,45 \\
\hline 7 & JSTOR & 4 & 2,45 \\
\hline 8 & Bibliotheek Arnhem, Belanda & 1 & 0,61 \\
\hline & JUMLAH & 163 & 100 \\
\hline
\end{tabular}

Sumber: Data Primer Diolah 2015

Karya Bung Hatta terdiri dari 159 judul buku dan 4 artikel jurnal. Meskipun Bung Hatta menulis banyak artikel, tetapi artikel tersebut telah dibukukan dalam surat kabar yang beliau pimpin yaitu 4 jilid surat kabar Daulat Ra'jat. Disamping itu beberapa karangan dikumpulkan dan dibukukan dalam beberapa jilid yaitu 5 jilid buku kumpulan karangan, serta 4 kumpulan pidato. 


\section{Jenis Karya}

Tabel 3. Jenis karya Bung Hatta

\begin{tabular}{llll}
\hline No. & Jenis karya & Jumlah & Keterangan \\
\hline 1 & Buku & 159 & $\begin{array}{l}4 \text { jilid surat kabar, } 5 \text { jilid kumpulan karangan, } \\
4 \text { kumpulan pidato }\end{array}$ \\
2 & Artikel & 4 & \\
\hline
\end{tabular}

Sumber: Data Primer Diolah 2015

\section{Subyek Kajian}

Karya Bung Hatta mengkaji berbagai bidang studi, berdasarkan klasifikasi maka ilmu-ilmu sosial adalah yang paling besar terdiri 106 judul, disusul sejarah 31 judul, dan14 karya umum berupa kumpulan karangan dan surat kabar yang dibukukan.
Sejumlah 106 judul karya di bidang ilmu sosial, 24 judul mengkaji koperasi, 21 judul mengkaji ekonomi, 45 judul mengkaji politik, 5 judul mengkaji bidang pendidikan, serta 2 judul di bidang hukum.

Tabel 4. Subyek karya Bung Hatta

\begin{tabular}{|l|r|r|r|r|r|r|r|r|r|r|}
\hline No.klas/subyek & 000 & 100 & 200 & 300 & 400 & 500 & 600 & 700 & 800 & 900 \\
\hline Jumlah & 14 & 5 & 3 & 106 & & 1 & 1 & & 2 & 31 \\
\hline
\end{tabular}

Sumber: Data Primer Diolah 2015

\section{ProduktivitasAkumulatif}

Bung Hatta dilahirkan 12 Agustus 1902, dan wafat pada 14 Maret 1980. Dalam rentang waktu 78 tahun usianya, beliau telah menghasilkan 163 judul karya. Tabel 4 terlihat bahwa Bung Hatta mencapai usia paling produktif yaitu pada usia 78 tahun, tahun
1980 , menjelang wafat, yaitu 11 judul. Sèdangkan pada tahun 1957, beliau menghasilkan 9 judul, pada usia 55tahun. Sebanyak 136 judul diterbitkan semasa beliau masih hidup, dan 27 judul diterbitkan setelah beliau wafat.

Tabel 5. Produktivitas akumulatif

\begin{tabular}{cccccccc}
\hline Tahun & Jumlah karya & Akumulatif & Usia & Tahun & Jumlah karya & Akumulatif & Usia \\
\hline 1926 & 1 & 1 & 24 & 1967 & 3 & 97 & 65 \\
1927 & 1 & 2 & 25 & 1968 & 3 & 100 & 66 \\
1928 & 1 & 3 & 26 & 1969 & 2 & 102 & 67 \\
1931 & 2 & 5 & 29 & 1970 & 5 & 107 & 68 \\
1932 & 1 & 6 & 30 & 1971 & 3 & 110 & 69 \\
1933 & 1 & 7 & 31 & 1972 & 3 & 113 & 70 \\
1934 & 2 & 9 & 32 & 1974 & 1 & 114 & 72 \\
1937 & 1 & 10 & 35 & 1975 & 2 & 116 & 73 \\
1939 & 1 & 11 & 37 & 1977 & 4 & 120 & 75 \\
1942 & 2 & 13 & 40 & 1978 & 2 & 122 & 76 \\
1943 & 1 & 14 & 41 & 1979 & 3 & 125 & 77 \\
1944 & 1 & 15 & 42 & 1980 & 11 & 136 & 78 \\
1945 & 2 & 17 & 43 & 1981 & 3 & 139 & \\
1946 & 5 & 22 & 44 & 1982 & 2 & 141 & 142 \\
1947 & 2 & 24 & 45 & 1983 & 1 & 144 & \\
1948 & 3 & 27 & 46 & 1985 & 2 & 145 & \\
1949 & 3 & 30 & 47 & 1986 & 1 & 2 & 147
\end{tabular}




\begin{tabular}{ccccccc}
\hline Tahun & Jumlah karya & Akumulatif & Usia & Tahun & Jumlah karya & Akumulatif \\
\hline 1951 & 4 & 40 & 49 & 1988 & 1 & 148 \\
1952 & 4 & 44 & 50 & 1992 & 1 & 149 \\
1953 & 8 & 52 & 51 & 1993 & 1 & 150 \\
1954 & 6 & 58 & 52 & 1994 & 1 & 151 \\
1955 & 5 & 63 & 53 & 1995 & 1 & 152 \\
1956 & 4 & 67 & 54 & 1998 & 1 & 153 \\
1957 & 9 & 76 & 55 & 2001 & 1 & 154 \\
1958 & 5 & 81 & 56 & 2002 & 4 & 158 \\
1959 & 1 & 82 & 57 & 2004 & 1 & 159 \\
1960 & 1 & 83 & 58 & 2008 & 1 & 160 \\
1961 & 1 & 84 & 59 & 2011 & 1 & 162 \\
1963 & 1 & 85 & 61 & 2012 & 1 & 163 \\
1965 & 1 & 86 & 63 & 2015 & 1 & \\
1966 & 8 & 94 & 64 & 2016 & & 162 \\
\hline
\end{tabular}

Sumber: Data Primer Diolah 2015

\section{Produktivitas Per Dasawarsa}

Produktivitas yang dicapai Bung Hatta tertinggi yaitu pada dasawarsa 1951-1960, pada usia 49-58 tahun, sejumlah 47 judul; disusul 1971-1980 pada usia 69-78 tahun, sejumlah 29 judul.

Tabel 6. Produktivitas per dasa warsa

\begin{tabular}{cccccc}
\hline Dasa warsa & Usia & Jumlah karya & Dasa warsa & Usia & Jumlah karya \\
\hline $1921-1930$ & $19-28$ & 3 & $1971-1980$ & $69-78$ & 29 \\
$1931-1940$ & $29-38$ & 8 & $1981-1990$ & & 12 \\
$1941-1950$ & $39-48$ & 25 & $1991-2000$ & 5 \\
$1951-1960$ & $49-58$ & 47 & $2001-2010$ & 7 \\
$1961-1970$ & $59-68$ & 24 & $2011-2015$ & 3 \\
\hline
\end{tabular}

Sumber: Data Primer Diolah 2015

\section{Tempat Terbit}

Karya Bung Hatta sebagian besar terbit di Jakarta sebanyak 108 judul, Yogyakarta sebanyak 11 judul, Bandung sebanyak 8 judul, Bukittinggi sebanyak5 judul, New York sebanyak4 judul, Berkeley sebanyak2 judul, dan Den Haag sebanyak2 judul. Sebanyak 142 judul diterbitkan di dalam negeri, dan 21 judul di luar negeri.

Tabel 7. Tempat terbit karya Bung Hatta

\begin{tabular}{lcclcc}
\hline Kota & Jumlah & DN/LN & Kota & Jumlah & DN/LN \\
\hline Djakarta & 108 & DN & Bogor & 1 & DN \\
Djokjakarta & 11 & DN & Chatillon-sous-Bagneux & 1 & LN \\
Bandung & 8 & DN & Honolulu & 1 & LN \\
Bukittinggi & 5 & DN & Kuantan & 1 & LN \\
New York & 4 & LN & LA HAYE & 1 & LN \\
Berkeley, CA & 2 & LN & New Delhi, & 1 & LN \\
DEN HAAG & 2 & LN & Padang Pandjang & 1 & DN \\
Makassar & 2 & DN & Pasuran & 1 & DN
\end{tabular}




\begin{tabular}{lcclcc}
\hline Kota & Jumlah & DN/LN & Kota & Jumlah & DN/LN \\
\hline Surabaya : & 2 & DN & Peking & 1 & LN \\
Tokyo & 2 & LN & Roma & 1 & LN \\
Biak & 1 & & s-Gravenhage & 1 & LN \\
Leiden & 1 & LN & Singapore & 1 & LN \\
Manokwari & 1 & DN & The Hague, Paris & 1 & LN \\
Siantar & 1 & DN & & & \\
\hline
\end{tabular}

Sumber: Data Primer Diolah 2015

\section{Penerbit}

Karya Bung Hatta sebagian besar diterbitkan oleh Kementerian Penerangan RI, sejumlah 25 judul;disusul Idayu Press 15 judul, Angkasa 6 judul, Tintamas 6 judul, dan Djambatan 5 judul.

Tabel 8 Penerbit karya Bung Hatta

\begin{tabular}{lrlrlr}
\hline \multicolumn{1}{c}{ Penerbit } & Jumlah & \multicolumn{1}{c}{ Penerbit } & Jumlah & Penerbit & Jumlah \\
\hline Kementerian & & & & & \\
Penerangan & 25 & Gunung Agung & 3 & Bulan Bintang & 2 \\
Idayu Press & 15 & Fasco & 3 & Cornell University Press & 2 \\
s.n. & 11 & Mutiara & 3 & Council on Foreign Relations & 2 \\
Angkasa & 6 & Pembangunan & 3 & Dekopin, & 2 \\
Tintamas & 6 & Penerbit Sinar Harapan & 3 & LP3ES & 2 \\
Djambatan & 5 & Perhimpoenan Indonesia & 3 & Penerbit Buku Kompas, & 2 \\
Balai buku Indonesia & 4 & Bina Ilmu, & 2 & Tjerdas & 2 \\
Endang & 4 & Balai Pustaka, & 2 & & \\
\hline
\end{tabular}

Sumber: Data Primer Diolah 2015

\section{Penerbitan Jurnal}

Karya Bung Hatta yang diterbitkan dalam bentuk artikel jurnal, ditemukan sejumlah 5 artikel, 4 di database JSTOR dan 1 di Ebsco. Sedangkan karya beliau dalam bentuk artikel surat kabar sebagian telah dibukukan dalam4 jilid surat kabar yang beliau beliau pimpin yaitu Daulat Ra'jat.

Tabel 9. Penerbitan jurnal karya Bung Karno

\begin{tabular}{|c|c|c|c|c|}
\hline No & Judul artikel & Jurnal & Penerbit & Sumber \\
\hline 1 & $\begin{array}{l}\text { One Indonesian View of } \\
\text { the Malaysia Issue }\end{array}$ & $\begin{array}{l}\text { Asian Survey, Vol. 5, No. } 3 \\
\text { (Mar., 1965), pp. 139-143 }\end{array}$ & $\begin{array}{l}\text { Univ. of } \\
\text { California Press }\end{array}$ & $\begin{array}{l}\text { http://www.jstor.org/stable } \\
/ 2642403\end{array}$ \\
\hline 2 & $\begin{array}{l}\text { Colonialism and the } \\
\text { Danger of War }\end{array}$ & $\begin{array}{l}\text { Asian Survey, Vol. 1, No. } 9 \\
\text { (Nov., 1961), pp. 10-14 }\end{array}$ & $\begin{array}{l}\text { Univ. of } \\
\text { California Press }\end{array}$ & $\begin{array}{l}\text { http://www.jstor.org/stable } \\
/ 3023504 \text {. }\end{array}$ \\
\hline 3 & $\begin{array}{l}\text { Indonesia between the } \\
\text { Power Blocs }\end{array}$ & $\begin{array}{l}\text { Foreign Affairs, Vol. 36, No. } \\
3 \text { (Apr., 1958), pp. 480-490 }\end{array}$ & $\begin{array}{l}\text { Council on } \\
\text { Foreign } \\
\text { Relations }\end{array}$ & $\begin{array}{l}\text { http://www.jstor.org/stable } \\
/ 20029302 \text {. }\end{array}$ \\
\hline 4 & Indonesia's Foreign Policy & $\begin{array}{l}\text { Foreign Affairs, Vol. 31, No. } \\
3 \text { (Apr., 1953), pp. 441-452 }\end{array}$ & $\begin{array}{l}\text { Council on } \\
\text { Foreign } \\
\text { Relations }\end{array}$ & $\begin{array}{l}\text { http://www.jstor.org/stable } \\
/ 20030977 \text {. }\end{array}$ \\
\hline 5 & $\begin{array}{l}\text { Democracy and Peace : } \\
\text { The Aims of our foreign } \\
\text { Policy }\end{array}$ & $\begin{array}{l}\text { Vital Speeches of the day, } \\
16 / 11 / 1955 \text {, pp. } 421-425\end{array}$ & $\begin{array}{l}\text { Indian Council } \\
\text { of World } \\
\text { Affairs }\end{array}$ & http://web.b.ebscohost.com \\
\hline
\end{tabular}

Sumber: Data Primer Diolah 2015 


\section{Karya yang Diterjemahkan}

Sejauh penelusuran yang dilakukan peneliti, ditemukan 8 judul karya Bung Hatta yang telah diterjemahkan ke berbagai bahasa, yaitu dapat dilihat dalam tabel 10 .

Tabel 10. Karya yang diterjemahkan

\begin{tabular}{|c|c|c|c|c|c|}
\hline No & Judul & $\begin{array}{l}\text { No.Klas/su } \\
\text { byek }\end{array}$ & Impresum & Bhs & Sumber \\
\hline \multirow[t]{3}{*}{1} & $\begin{array}{l}\text { Bung Hatta antwoordt : een vraaggesprek met Dr. Z. Yasni, } \\
\text { opgenomen in } 1978 \text { ten huize van Dr. Moh. Hatta by } \\
\text { Mohammad Hatta; Zainul Yasni }\end{array}$ & 320.958 & $\begin{array}{l}\text { Hengelo: Uitgeverij Smit } \\
\text { van } 1876,1979\end{array}$ & Belanda & Worldcat \\
\hline & $\begin{array}{l}\text { Bung Hatta's Answers : Interview Dr. Mohammad Hatta with } \\
\text { Dr. Z. Yasni }\end{array}$ & $\begin{array}{l}049.3 \text { Hat b } \\
\text { c. } 2\end{array}$ & $\begin{array}{l}\text { Singapore: Gunung } \\
\text { Agung, } 1981\end{array}$ & Inggris & $\begin{array}{l}\text { Hatta } \\
\text { Corner }\end{array}$ \\
\hline & $\begin{array}{l}\text { Bung Hatta Menjawab : wawancara Dr. Mohammad Hatta } \\
\text { dengan Dr. Z. Yasni }\end{array}$ & $\begin{array}{l}92 \text { yas b } \\
c .1\end{array}$ & $\begin{array}{l}\text { Jakarta: Gunung Agung, } \\
1979\end{array}$ & Indonesia & $\begin{array}{l}\text { Hatta } \\
\text { Corner }\end{array}$ \\
\hline \multirow[t]{2}{*}{2} & Our democracy by Mohammad Hatta; Robert Cook & & $\begin{array}{l}\text { Nathan : Griffith University, } \\
1979\end{array}$ & Inggris & Worldcat \\
\hline & Demokrasi Kita & $\begin{array}{l}321.7 \text { Hat d } \\
\text { c. } 1\end{array}$ & $\begin{array}{l}\text { Djakarta: Pustaka Antara, } \\
1966\end{array}$ & Indonesia & $\begin{array}{l}\text { Hatta } \\
\text { Corner }\end{array}$ \\
\hline \multirow[t]{2}{*}{3} & $\begin{array}{l}\text { How Far Have We Got? Radio address by the vice } \\
\text { president of the Republic of Indonesia, Mohammad Hatta, } \\
\text { on the eve of the Ivth Cooperatives Day, 11th July, } 1954\end{array}$ & $\begin{array}{l}334 \text { Hath } \\
\text { c.2 }\end{array}$ & $\begin{array}{l}\text { Djakarta: Ministry of } \\
\text { Information Republic of } \\
\text { Indonesia, } 1954\end{array}$ & Inggris & $\begin{array}{l}\text { Hatta } \\
\text { Corner }\end{array}$ \\
\hline & $\begin{array}{l}\text { Sampai dimanakah kita? / amanat dan pidato radio pada } \\
\text { Hari Koperasi ke IV / Wakil Presiden Mohammad Hatta. }\end{array}$ & 334 & $\begin{array}{l}\text { [Djakarta]: Kementerian } \\
\text { Penerangan, [1954] }\end{array}$ & Indonesia & Hathitrust \\
\hline \multirow[t]{2}{*}{4} & $\begin{array}{l}\text { Past and Future by Mohammad Hatta. Translation series, } \\
\text { Modern Indonesia Project }\end{array}$ & 378.4 & $\begin{array}{l}\text { Ithaca New York } \\
\text { Cornell Univ., } 1960\end{array}$ & Inggris & Worldcat \\
\hline & $\begin{array}{l}\text { Lampau Dan Datang: Pidato Diutjapkan Pada Penerimaan } \\
\text { Gelar Doctor Honoris Causa Dari Universitas Gadjah Mada } \\
\text { Pada } 27 \text { Nopember } 1956\end{array}$ & $\begin{array}{l}378.4 \text { Hat } 1 \\
\text { c. } 1\end{array}$ & $\begin{array}{l}\text { [Djakarta]: Djambatan, } \\
1956\end{array}$ & Indonesia & $\begin{array}{l}\text { Hatta } \\
\text { Corner }\end{array}$ \\
\hline \multirow[t]{2}{*}{5} & Islam Masjarakat Demokrasi Dan Perdamaian & $\begin{array}{l}304 \text { Hat i } \\
\text { c. } 1\end{array}$ & $\begin{array}{l}\text { Djakarta: Tintamas, } \\
1957\end{array}$ & Indonesia & $\begin{array}{l}\text { Hatta } \\
\text { Corner }\end{array}$ \\
\hline & $\begin{array}{l}\text { Islam Society Democracy \& Peace : speech delivered during } \\
\text { his visit to India }\end{array}$ & $\begin{array}{l}042 \text { Hat I } \\
\text { c. } 1\end{array}$ & $\begin{array}{l}\text { New Delhi: Embassy of } \\
\text { the Republic of Indonesia } \\
\text { in India, [1955] }\end{array}$ & Inggris & $\begin{array}{l}\text { Hatta } \\
\text { Corner }\end{array}$ \\
\hline \multirow[t]{2}{*}{6} & Democracy and Peace : The Aims of our foreign Policy & 992 & $\begin{array}{l}\text { S.l.: Indian Council of } \\
\text { World Affairs, } 1955\end{array}$ & Inggris & Ebsco \\
\hline & $\begin{array}{l}\text { Demokrasi dan Perdamaian diutjapkan di Indian Council of } \\
\text { World Affair, New Delhi } 16 \text { Nopember } 1955 \text {, dihadapkan } \\
\text { kepada Madjelis Soatsoal International India }\end{array}$ & 992 Hat $m$ & s.l.: s.n., 1955 & Indonesia & $\begin{array}{l}\text { Hatta } \\
\text { Corner }\end{array}$ \\
\hline \multirow[t]{2}{*}{7} & $\begin{array}{l}\text { Sixth international conference on Asian history International } \\
\text { Association of Historians of Asia (I.A.H.A.) Yogyakarta, } \\
\text { August 25-30, 1974 / Mohammad Hatta }\end{array}$ & $950[20]$ & [s.l. :]: s.n., 19-? & Inggris & PNRI \\
\hline & $\begin{array}{l}\text { Berpartisipasi dalam Perjuangan Kemerdekaan Nasional } \\
\text { Indonesia: Pidato pada conference of International Asso } \\
\text { ciation of Historians of Asia di Yogyakarta, Agustus } 1974\end{array}$ & $\begin{array}{l}991 \text { Hat b } \\
\text { c. } 2\end{array}$ & $\begin{array}{l}\text { Jakarta: Yayasan Idayu, } \\
1980\end{array}$ & Indonesia & $\begin{array}{l}\text { Hatta } \\
\text { Corner }\end{array}$ \\
\hline \multirow[t]{3}{*}{8} & $\begin{array}{l}\text { Indonesië vrij! : onuitgesproken, aan de rechtbank } \\
\text { overgelegde, rede, ter verdediging van de "Perhimpoenan } \\
\text { Indonesia" naar aanleiding van het proces tegen de } \\
\text { Indonesische studenten by Moh Hatta; Edo Fimmen : } 24 \\
\text { September '28 }\end{array}$ & 959.8 & $\begin{array}{l}\text { DEN HAAG: } \\
\text { Perhimpoenan Indonesia, } \\
1928\end{array}$ & Belanda & $\begin{array}{l}\text { Bibliotheek } \\
\text { Arnhem }\end{array}$ \\
\hline & Indonesia merdeka, diterjemahkan Drs. Hazil tanzil & 959.8 & $\begin{array}{l}\text { Jakarta: Bulan Bintang, } \\
1976\end{array}$ & Indonesia & $\begin{array}{l}\text { Bibliografi } \\
\text { Idayu }\end{array}$ \\
\hline & $\begin{array}{l}\text { Mohammad Hatta: Indonesia Merdeka (Indonesie Vrij): } \\
\text { Pidato Pembelaan Bung Hatta di Den Haag } 1928\end{array}$ & $\begin{array}{l}959.8022 / \\
\text { Moh / - }\end{array}$ & $\begin{array}{l}\text { Yogyakarta: Aditya Media } \\
\text { bekerjasama dengan } \\
\text { Pusat Studi Ekonomi } \\
\text { Pancasila UGM, 2005 }\end{array}$ & Indonesia & $\begin{array}{l}\text { Katalog } \\
\text { perpustaka } \\
\text { an UGM }\end{array}$ \\
\hline
\end{tabular}

Sumber: Data Primer Diolah 2015 


\section{Kontribusi Bung Hatta}

Meskipun karya-karya Bung Hatta terdiri dari berbagai bidang studi, tetapi kontribusi terbesar adalah dalam bidang politik, ekonomi, ekonomi kerakyatan dan hak asasi manusia. 163 judul apabila dikelompokkan menjadi, 24 judul mengkaji ekonomi koperasi, 21 judul mengkaji ekonomi, 45 judul mengkaji politik. Salah satu buku karya beliau yang terkenal, yang juga merupakan naskah pembelaan Bung Hatta pada saat menghadapi sidang pengadilan Den Haag, 28 Maret 1928 berjudul "Indonesie Vrij!" disusun sewaktu beliau sebagai mahasiswa berusia 26 tahun yang berada di dalam penjara. Karya tersebut telah diterjemahkan beberapa kali. Pada tahun 1930, Ir. Soekarno juga menyusun naskah pembelaan berjudul "Indonesia Menggugat", untuk menghadapi pengadilan (landraad) Bandung. Karena dituduh melalui partai yang dipimpinnya, Partai Nasional Indonesia, akan memberontak terhadap pemerintah yang sah, pemerintah Hindia-Belanda. Ir. Soekarno akhirnya dihukum 4 tahun penjara. Karya-karya para tokoh pejuang, yang juga sangat terkenal juga ditulis dari dalam penjara diantaranya "Babad Diponegoro: yang disusun sewaktu beliau berada dalam pengasingan di Menado. Babad Diponegoro akhirnya diterima sebagai naskah manuskrip memory of the world di Unesco. Demikian juga buku berjudul "Long Walk to Freedom: The Autobiography of Nelson Mandela karya Nelson Mandela. Sedangkan "Mein kampf" meskipun juga terkenal, tetapi disusun oleh Adolf Hitler yang dinyatakan sebagai penjahat perang dan genoside terbesar dalam sejarah.

\section{Bidang Hak Asasi Manusia}

Akbar (2009), mengemukakan beberapa argumen pada saat menyampaikan pokok-pokok pikiran penganugerahan Bung Hatta award di bidang HAM. Bahwa Bung Hatta adalah seorang tokoh, pelopor dan perintis perjuangan hak asasi manusia di Indonesia. Beliau dinilai sebagai salah seorang peletak dasar utama negara demokrasi konstitusional yang modern, baik dalam tataran nilai-nilai maupun praktek pelembagaannya. Naskah pembelaannya di negeri Belanda, Indonesia Vrij!, pada tahun 1928 telah menggemparkan negeri Belanda, adalah perlawanannya terhadap penindasan dan keterhinaan rakyat jajahan.Pandangan Bung Hatta menempatkan kedaulatan rakyat di posisi yang utama, janganmerendahkan kedaulatannya, dan melawan suara nuraninya. Beliau juga telah dinilai sebagai pelopor demokrasi. Pada 3 November 1945, pemerintah mengeluarkan maklumat yang ditandatangani Bung Hatta sebagai Wakil Presiden yang menyerukan pembentukan partai-partai politik, yang dengan demikian menggarisbawahi penghapusan negara berpartai tunggal. Padahal pandangan sebagian elite politik ketika itu banyak yang lebih setuju dengan ide partai tunggal, yaitu Partai Nasional Indonesia. Beliau yakin bahwa agar dapat mempertahankan eksistensinya, Indonesia memerlukan partisipasi yang luas dari masyarakat, masyarakat tidak bersifat tunggal, tetapi terdiri dari berbagai golongan dan aliran politik. Beliau berpandangan dengan kemajemukan politik yang hendak dibangun, Indonesia bersatu dalam kebhinnekaan dan bhinneka dalam kesatuan.

\section{Bidang Ekonomi}

Arief (2014) menjelaskan bahwa karya Bung Hatta berjudul "Ekonomi Ra'jat dalam Bahaja", yang dimuat di surat kabar yang beliau pimpin, Daulat Ra'jat Tahun ke IV, 10 Januari 1934, No. 84, halaman 2-4 telah menjadi dasar konsep ekonomi kerakyatan sebagai tandingan untuk mengenyahkan sistem ekonomi kolonial Belanda yang didukung/dibantu oleh kaum aristokrat dalam sistem feodalisme di dalam negeri dan pihak-pihak swasta asing tertentu sebagai komprador pihak kolonial Belanda. Beliau juga yang pertama kali menggunakan istilah "ekonomi ra'jat" yaitu dalam artikelnya yang dimuat di Daulat Ra'jat, 20 November 1931, Tahoen ke-I no.7, halaman 1-4, berjudul "Pengaroeh Koloniaal Kapitaal di Indonesia". Lebih lanjut, Suma (2014) menjelaskan bahwa Bung Hatta mempunyai konsep ekonomi kerakyatan yaitu sistem koperasi yang berasaskan kekeluargaan. Bahwa perekonomian disusun sebagai usahabersama berdasar pada asas kekeluargaan. Koperasi adalah contoh bangun perusahaan yang sesuai dengan konsep ekonomi kerakyatan yang tertuang dalam konstitusi, Bung Hatta adalah juga inspirator pasal 33 UUD 1945. Bung Hatta berpandangan, "demokrasi tidak lengkap, apabila tidak berlaku kedua-dua seginja, demokrasi politik dan ekonomi" (Hatta, 1960:38).

\section{Bidang Politik}

Karya Bung Hatta berupa buku berjudul "Mendajung Antara Dua Karang: Keterangan pemerintah diutjapkan dimuka Sidang BPKNP di Djokja pada tahun 1948, diterbitkan oleh Kementerian penerangan tahun 1951, menjadi legenda dan sampai sekarang tetap menjadi pedoman dalam menjalankan kebijakan politik luar 
negeri RI yang bebas dan aktif. Waluyo dan Masykur (2012) menyatakan bahwa buku tersebutmerupakan pernyataan sikap pemerintah secara formal tertulisyang pertama, dalam menghadapi situasi dunia internasional. Sikap politik tersebut di kemudian hari dikenal sebagai "politik bebas aktif", dan menjadi dasar bagi pelaksanaan politik luar negeri Indonesia sampai sekarang. Argumen Bung Hatta dalam buku tersebut, telah teruji menghadapi berbagai serangan pengaruh tokoh-tokoh yang condong memihak dua kekuatan utama yang berebut pengaruh, yaitu blok barat dan blok timur. Karya Bung Hatta di bidang politik luar negeri juga diterbitkan dalam bentuk artikel berjudul "Indonesia's Foreign Policy", dimuat di jurnal Foreign Affairs, Vol. 31, No. 3 (Apr., 1953), pp. 441 452; serta "Indonesia between the Power Blocs", yang juga dimuat di Jurnal Foreign Affairs, Vol. 36, No. 3 (Apr., 1958), pp. 480-490.

\section{KESIMPULAN}

Bung Hatta merupakan tokoh pejuang proklamator kemerdekaan, wakil presiden RI pertama, tokoh pergerakan nasional, tokoh pendidikan, bapak koperasi Indonesia. Beliau juga seorang ilmuwan dan penulis yang sangat produktif. Jenis-jenis karya Bung Hatta meliputi Bung Hatta mencapai masa paling produktif pada usia 49-58 tahun, yaitu pada dasawarsa 1951-1960, dengan 47 judul karya. Kontribusi terbesar beliau adalah pada bidang hak asasi manusia, politik dan ekonomi kerakyatan. Karya-karya beliau telah teruji menghadapi tantangan perubahan zaman, dan tetap menjadi pedoman pelaksanaan pemerintahan Republik lndonesia.

1) Untuk mengetahui jenis-jenis karya Bung Hatta dan kontribusinya.

2) Untuk mengetahui subyek karya yang dihasilkan, di Hatta Corner.

3) Untuk mengetahui produktivitas Bung Hatta sebagai penulis.

4) Untuk mengetahui penerbitan karya-karya Bung Hatta selama berkarya.

\section{SARAN}

Buku-buku karya Bung Hatta yang nampak lusuh dan sebagian telah mulai rapuh, ternyata berisi pengetahuan yang tidak ternilai harganya, dan tetap relevan dengan perkembangan zaman. Karena itu, manajemen koleksi langka perlu ditingkatkan, baik mclalui preservasi isi dengan alihmedia, perbaikan data bibliografi, maupun berbagai bentuk kerjasama.

\section{DAFTAR PUSTAKA}

Akbar, Patrialis. 2009. Pokok-Pokok Pikiran Penganugerahan Bung Hatta Award di Bidang HAM. Seminar Tentang Pemikiran Bung Hatta dan Perkembangan HAM di Indonesia. Jakarta, 9 Desember 2009

Arief, Sritua. 2014. EPILOG Melihat Gagasan Ekonomi RakyatBung Hatta Sebagai Pijakan KonsepsiEkonomi Kerakyatan. Dalam (Mubyarto dkk.). 2014. Ekonomi Kerakyatan. Jakarta: Lembaga Suluh Nusantara dan American Institute for Indonesian Studies (AIFIS).Hlmn. I77-186

Baby, K. dan J.P.S. Kumaravel. 2012. BioBibliometrics Analysis of Literature Output of Prof. M. Lakshmanan in the Subject of Nonlinear Dynamics. Asia Pacific Journal of Library and Information Seience. Vol.2 No.2 (Jul-Dec 2012)

Diodato, Virgil Pasquale. 1994. "Dictionary of Bibliometrics". Binghamton, New York : Haworth Press.

Ensiklopedi Tokoh Indonesia. 2002. http://www.tokohindonesia.com/, 23 Oktober $2014 \mathrm{pk} 15.20 \mathrm{pm}$

Hartinah, Sri. 2002. Analisis Sitiran (Citation Analysis). Dalam Kumpulan Makalah Kursus Bibliometrika. Jakarta : Masyarakat Informetrika Indonesia

Hatta, Mohammad. 1960. Ekonomi Terpimpin. Djakarta: Fasco

2002. Mohammad Hatta : Memoir Terbitan Khusus Satu Abad Bung Hatta. Jakarta: Yayasan Hatta 